\section{LIBRo El arte de no enseñar lengua}

Cantero Serena, F. J. (2019)

Barcelona: Octaedro. 98 págs.

ISBN: 8417667474

Recepción: 18/06/2020 | Revisión: 18/06/2020 | Aceptación: 19/07/2020

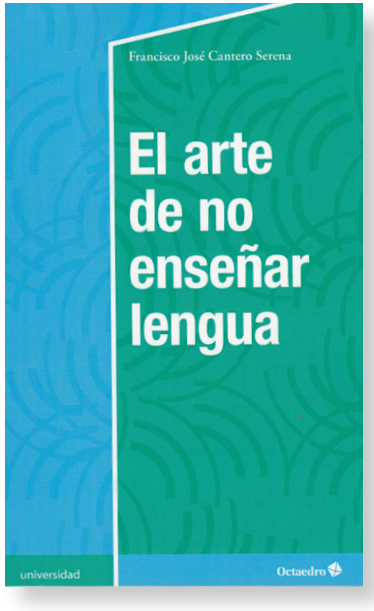

¿Si soy profesor, cómo no voy a enseñar lengua? Es la primera reacción al leer el título de este libro porque, tradicionalmente, la preocupación didáctica se ha basado en los procesos de enseñanza: qué enseñar, cuándo y cómo hacerlo. La inclusión del adverbio negativo tanto en el título como en cinco de los seis capítulos del libro es una provocación para motivar a su lectura al profesorado de didáctica de la lengua. En El arte de no enseñar lengua Cantero reflexiona y da respuesta en cómo gestionar la enseñanza de la adquisición de lenguas con un cambio de paradigma: hay que enseñar a comunicarse. Desde el primer capítulo, « Arte de contagiar», explicita que la diferencia está en que no debemos entender la comunicación como la teoría de la información (Shannon y Weaver, 1949), sino desde una perspectiva diferente, como relación personal.

El objetivo es que el alumnado adquiera competencias, se convierta en un hablante eficaz de la lengua, ya sea un hablante de su propia lengua, de segunda lengua (L2) o de lengua extranjera (LE); y que el profesor cambie su papel en el aula porque no enseña lengua, sino que la gestiona, la facilita y ayuda al alumnado a adquirir competencia comunicativa. Así pues, en el segundo capítulo, «No enseñar», queda claro que hay que promover competencias y habilidades porque la comunicación es un saber.

A nuestro entender, el tercer capítulo, «No enseñar qué: las competencias comunicativas», es el que reviste más interés, puesto que, en primer lugar, revisa la enseñanza de la lengua en el aula tradicional, los objetivos que, a menudo, no se consiguen en la comunicación oral porque se confunde la competencia comunicativa con la competencia lingüística y porque, en segundo lugar, describe el cambio de paradigma que se debe promover (y no enseñar): la adquisición de todas las competencias comunicativas. 
Junto a un repaso de las competencias estratégicas, el autor se detiene a profundizar y explicar las cuatro destrezas tradicionales (hablar, entender, escribir y leer), que considera que forman parte de una perspectiva clásica, y apuesta por las actividades y estrategias comunicativas que propuso el Marco Común Europeo de Referencia (2001) por ser más ricas y realistas.

Según Cantero, la competencia estratégica tiene que ser el objetivo prioritario para que nuestros alumnos sean capaces de elaborar y gestionar todos sus recursos comunicativos, sus saberes y sus habilidades, los cuales ha ido desarrollando a lo largo de su vida. Esta competencia es el eje y el motor de las demás: la lingüística, la discursiva y la cultural. Esta idea la refleja esquemáticamente con un juego de cuatro triángulos formando uno solo.

La competencia estratégica a su vez se subdivide en cuatro (sub)competencias específicas: la productiva (hacerse entender), la perceptiva (entender), la mediadora (entenderlos y hacerlos entender) y la interactiva (relacionarse con otros interlocutores). La larga trayectoria y experiencia del autor en el ámbito de la didáctica de la lengua le permiten expresar la complejidad de las cuatro competencias estratégicas y de sus cuatro competencias específicas de una manera clara y visual (4 triángulos que forman uno único). Y si además cada hablante maneja diversos códigos (verbales y no verbales; orales y escritos), esta multiplicidad de códigos la representa con la forma de una estrella, la estrella comunicativa, en que cada hoja simboliza la competencia comunicativa de un código. Así pues, el autor hace hincapié que el desarrollo de cada competencia dependerá de la historia del hablante, de qué contextos, qué interlocutores y qué necesidades comunicativas han definido su proceso, independientemente del idioma o idiomas que hable, puesto que se trata de un proceso personal, no lineal ni paralelo.

En el cuarto capítulo, «No enseñar qué: las habilidades lingüísticas», el autor propone un nuevo esquema, alternativo al clásico de los elementos de la comunicación (hablante-código (mensaje/canal)-oyente), en que se deben tener en cuenta otros códigos verbales: los prelingüísticos, los lingüísticos y los paralingüísticos; y los no verbales: los kinésicos, los proxémicos y los cronémicos, porque en la conversación hay que intercambiar, compartir y negociar. Además, se detiene a detallar estrategias que implican (no)enseñar comunicación oral y a valorar el lenguaje oral formal, atendiendo a que no dispone de intersubjetividad que no permite la interacción ni la negociación. Asimismo, hace hincapié en el lenguaje escrito, como comunicación que no es en tiempo real y lo compara con el discurso oral. A continuación, quizá en el subapartado menos novedoso, pero no por ello menos interesante, se recuerda la necesidad de la adecuación, coherencia y cohesión del texto escrito; la importancia de las 3 fases de composición: planificación, textualización (o redacción) y revisión (o corrección); y, finalmente, repasa los tipos de textos más comunes.

Cantero, en el quinto capítulo, «No enseñar cómo», responde a la pregunta clave 
de los profesores de didáctica de la lengua: ¿Cómo promover y gestionar la adquisición de competencias comunicativas por parte de nuestros alumnos?: promoviendo que las actividades sean significativas, que focalicen las distintas competencias y que se realicen adecuadamente. Si los alumnos tienen un contexto significativo y son interlocutores genuinos que están interesados en conseguir algo, el resultado será eficaz porque gozarán comunicando. En el aula, el enfoque por tareas y trabajar por proyectos les permite tener un contexto para desarrollar la actividad conjuntamente $y$, a su vez, ponerse de acuerdo.

El profesorado debe tener en cuenta que, si trabaja en un proyecto, las actividades deben cumplir unos requisitos indispensables: tienen que estar secuenciadas, ser significativas, estar integradas y estar dirigidas a una tarea final. Además, el docente debe tener en cuenta que los interlocutores son los alumnos, no el profesor; de este modo, desarrollan sus competencias y habilidades, que es el objetivo didáctico. Se incide en que la evaluación formativa, en la que los propios alumnos son partícipes, potencie el proceso de la adquisición de sus competencias.

A partir de ejemplos, el autor propone que las actividades que se realicen para la tarea final sean de diferentes categorías: tareas posibilitadoras, tareas capacitadoras, tareas previas, tareas de autoevaluación y tareas derivadas. Cantero cree que la evaluación clásica no sirve para enseñar porque evaluar productos no permite al alumno progresar. En cambio, es partidario de la evaluación formativa como herramienta de intervención en el proceso del alumno y considera claves la autoevaluación y la coevaluación.

Y, finalmente, en el último capítulo, «No enseñar quién», se centra en los cambios de rol del profesor porque debe abandonar el rol de corrector, debe ser un facilitador y un orientador del trabajo de sus alumnos. También debe abandonar el rol de disciplinador para ser un planificador, un punto de referencia, un gestor de la comunicación en el aula, un contagiador de actitudes y de entusiasmo, y un orientador, entre otros.

En definitiva, a lo largo de los seis capítulos que constituyen esta obra, Cantero nos presenta un excelente material para reflexionar sobre la competencia estratégica y comunicativa y, a su vez, una herramienta esencial y básica para practicar en el arte de comunicarse en las asignaturas de didáctica de la lengua cambiando las funciones del profesor de lengua. Estamos, pues, ante un texto en el que se constata de una forma clara y didáctica que, si eres profesor y quieres enseñar lengua, debes enseñar a los aprendientes a comunicarse. Y si comunicarse es contagiar, la lectura de «El arte de no enseñar lengua» contagia la necesidad de cambiar de paradigma en el aprendizaje-enseñanza de la didáctica de la lengua y en el rol de profesor. ¿Estás seguro de que no te quieres contagiar? 


\section{Referencias bibliográficas}

Council for Cultural Cooperation (2001). Common European framework of reference for languages: Learning, teaching, assessment. Estrasburgo: Consejo de Europa.
Shannon, C. E., y Weaver, W. (1949). The mathematical theory of communication. Illinois: University of Illinois. 